\title{
A Scaling Model for Estimating Time-Series Party Positions from Texts
}

\author{
Jonathan B. Slapin Trinity College, Dublin \\ Sven-Oliver Proksch University of California, Los Angeles
}

\begin{abstract}
Recent advances in computational content analysis have provided scholars promising new ways for estimating party positions. However, existing text-based methods face challenges in producing valid and reliable time-series data. This article proposes a scaling algorithm called WORDFISH to estimate policy positions based on word frequencies in texts. The technique allows researchers to locate parties in one or multiple elections. We demonstrate the algorithm by estimating the positions of German political parties from 1990 to 2005 using word frequencies in party manifestos. The extracted positions reflect changes in the party system more accurately than existing time-series estimates. In addition, the method allows researchers to examine which words are important for placing parties on the left and on the right. We find that words with strong political connotations are the best discriminators between parties. Finally, a series of robustness checks demonstrate that the estimated positions are insensitive to distributional assumptions and document selection.
\end{abstract}

$\mathrm{M}$ any theories of comparative politics rely on the ability of researchers to locate political parties in a policy space. Theories of coalition formation and duration use party positions to predict which governments form and how long they survive (Baron 1991; Crombez 1996; de Swaan 1973; Druckman and Thies 2002; Druckman, Martin, and Thies 2005; Strom 1984; Warwick 1992). Likewise, theories of lawmaking use distances between parties to predict policy change (Bawn 1999; Hallerberg and Basinger 1998; Tsebelis 2002), as do analyses of budgetary politics (Franzese 2002), globalization and the social welfare state (Garrett 1998), and labor politics (Wallerstein 1999). In fact, all tests of spatial models in comparative politics rely on the ability to estimate party positions.

Despite the importance of party positions to the study of comparative politics, locating parties in a political space over time is a difficult task. Although one might have a good intuition about where parties stand relative to each other, the positions themselves are abstract concepts that cannot be observed directly (Benoit and Laver 2006b, chap. 3). To facilitate empirical work, scholars have developed numerous methods for estimating party positions. The existing methodological arsenal includes expert surveys (Benoit and Laver 2006b; Castles and Mair 1984; Huber and Inglehart 1995; Laver and Hunt 1992), hand coding of party manifestos (Budge, Robertson, and Hearl 1987; Budge et al. 2001), and more recently computer coding of manifestos (Laver, Benoit, and Garry 2003). Despite the widespread use of these methods, we argue that they face several challenges in producing valid and reliable time-series position estimates. This leaves a gap in the literature on estimating party ideology.

This article presents a statistical model that adds to and improves upon the existing methodologies by estimating party positions, and their associated uncertainty, over time using word frequencies from manifestos. The remainder of the article reviews the existing methods for estimating party positions, then introduces a new model and compares it to other methods. Finally, we use this model to estimate party positions from manifestos in postreunification Germany. In addition, we describe the lexicon of German politics during this era. The new

Jonathan B. Slapin is lecturer in political science, Trinity College, University of Dublin, Dublin 2, Ireland (jonslapin@gmail.com).Sven-Oliver Proksch is PhD candidate, Department of Political Science, University of California, Los Angeles, CA 90095-1472 (proksch@ucla.edu).

We would like to thank Kathleen Bawn, Ken Benoit, Jim DeNardo, Tim Groseclose, James Honaker, Thomas König, Jeff Lewis, Will Lowe, Burt Monroe, George Tsebelis, several anonymous reviewers, and participants at the UCLA Methods Workshop and the 2007 annual meeting of the Midwest Political Science Association for their comments and suggestions. In addition, we thank the Zentralarchiv für Empirische Sozialforschung at the University of Cologne, Germany, for providing us with the German party manifestos in electronic format. The order of authors' names reflects the principle of rotation. Both authors have contributed equally to all work.

American Journal of Political Science, Vol. 52, No. 3, July 2008, Pp. 705-722 
estimates are robust to various model specifications, correlate highly with other estimates, but are indeed an improvement over previous party position estimates.

\section{Current Methods for Estimating Party Positions}

Party positions are unobservable and must therefore be treated as a latent variable in empirical work. Scholars face the challenge of measuring these underlying party positions and policy dimensions. Parties reveal their positions indirectly through a variety of activities. They publish manifestos prior to elections in which they state policy goals, they make political statements and speeches, and their members cast votes in parliaments (Benoit and Laver 2006b). Currently, there are three primary methods for estimating latent party positions. Hand coding and computer-based analysis of manifestos assume that election manifestos contain precise information about party positions at a particular point in time. Expert surveys measure the positions not from primary sources, but indirectly through judgments of country specialists who rely on a variety of sources beyond manifestos to form an opinion. ${ }^{1}$

\section{Expert Surveys}

In an ideal world, regularly conducted expert surveys may provide the best means for estimating party positions. Experts are able to synthesize large quantities of information from various sources, including manifestos, speeches, voting patterns, and media reports (Benoit and Laver 2006b). Moreover, surveys may be able to examine when new issues arise and determine their relative importance (Castles and Mair 1984; Huber and Inglehart 1995). Experts are able to tell researchers what, in their opinion, are the salient dimensions, rather than leaving the researcher to guess or assign arbitrary weights. From a pragmatic standpoint, however, expert surveys are difficult and expensive to repeat over time and across countries, requiring continuous sources of funding to conduct new surveys at regular intervals. Often, they require multilingual research teams. If a researcher realizes that a survey failed to include a question, it is impossible to go back in time to retrieve that information. Frequently, surveys phrase questions differently, making the comparisons across surveys question-

\footnotetext{
${ }^{1} \mathrm{~A}$ possible fourth method is to analyze the voting records of party members in legislatures. This is the most prominent approach used in presidential systems (e.g., roll-call analysis using NOMINATE [Poole and Rosenthal 1985]). However, in parliamentary systems voting patterns unsurprisingly reveal only a division between government parties and opposition parties due to high levels of party discipline and government agenda control (Laver 2006, 137).
}

able. Moreover, it is difficult to know whether different experts across countries and over time understand and answer the questions in a similar manner. While surveys often come up short as pooled cross-sectional time-series data, they do provide researchers with a method for checking the validity of position estimates from other methods in addition to providing a snapshot of party positions at one point in time (Gabel and Huber 2000).

\section{Hand Coding: Comparative Manifestos Project}

Probably the most well-known and widely used method for generating party positions is hand coding of party manifestos. The Comparative Manifestos Project (CMP; Budge, Robertson, and Hearl 1987; Budge et al. 2001) has greatly advanced the ability of scholars to conduct comparative research by providing estimates of party positions across countries and over time. The CMP group has created 56 issues, which fall into seven major categories. To generate party positions, the CMP group codes the number of quasi-sentences which fall into each issue and then divide by the total number of quasi-sentences in the manifesto to control for manifesto length. Thus, the score for each party for each issue is simply the percentage of total sentences which fall into this issue.

To calculate party positions on a left-right dimension from these data, scholars have employed several methods. Laver and Budge (1992) provide one of the more commonly used approaches. They identify several important issues as left-wing issues and others as right-wing issues. Then they simply sum the left-wing scores and the right-wing scores and subtract the right totals from the left totals. The problem is that not all 56 categories can be attributed to the left or to the right. Thus, even though two parties may discuss the left-wing issues in an identical manner, if one party mentions neutral issues while the other does not, the positions of these parties will be coded differently. ${ }^{2}$

In addition, left and right issues may vary across countries and over time. This may create problems for constructing a valid left-right scale. For example, in

\footnotetext{
${ }^{2}$ For example, imagine two parties with very short manifestos. The first party's manifesto reads: "We support more social welfare spending." The second party's manifesto reads: "We support more social welfare spending. Decisions about this spending should be made at the local levels." Because $100 \%$ of the first party's manifesto deals with a left-wing issue, the party's score on the left-right dimension would be 1, or as far left as possible. The second party's score, on the other hand, would be 0.5 by this coding scheme. The first sentence, $50 \%$ of the manifesto, falls into a left-wing category. The second sentence, however, deals with decentralization, an issue which is coded neither left nor right. We would not want to conclude, though, that party 1 is actually located to the left of party 2 simply because party 1 remained silent on a neutral issue.
} 
the United States, decentralization would probably be a right-wing issue while in other countries it may be a neutral issue, or even a left-wing issue. Moreover, it is not clear that all issues should be given the same weight in determining party positions, and weights may vary across countries and time. The fixed coding scheme of the CMP also means important new issues must be placed into existing categories (e.g., global terrorism after 9/11). Other categories may no longer be relevant (e.g., foreign special relations between West and East Germany after 1990).

There have been several attempts to fix the manifesto scheme. Gabel and Huber (2000), for example, suggest simply extracting the first principal component from the 56 issues, an approach they refer to as the vanilla method. Others have retained the seven main categories in the original dataset and then extracted principal components from each category (Klingemann 1995).

The hand-coding approach provides the only crosssectional time-series database on party positions to date. It has the advantage that researchers know exactly what issues are included in the left-right dimension because categories are defined. However, the coding scheme of leftright positions itself is problematic and can lead to invalid positions. Moreover, because the manifestos have been coded only once, researchers do not know the uncertainty associated with this technique. ${ }^{3}$ Finally, such a project is costly and difficult to replicate.

\section{Computer-Based Content Analysis}

The most recent innovation in estimating party positions involves computer-based content analysis of party manifestos. This method attempts to reduce both the costs and likelihood of human error associated with hand coding texts. Laver, Benoit, and Garry (2003) make great advances in computer-based content analysis by suggesting the use of reference texts rather than hand-coded dictionaries. ${ }^{4}$ Using this approach, researchers first identify reference texts known to represent the extremes of the political space (and possibly the center as well). This onedimensional space is anchored by assigning reference values to the reference texts, ideally obtained from previous

\footnotetext{
${ }^{3} \mathrm{~A}$ recent paper attempts to fix the uncertainty problem and generates confidence intervals by bootstrapping quasi-sentences (Benoit, Laver, and Mikhaylov 2007).

${ }^{4}$ Earlier computer coding schemes relied on linking texts with computer-based dictionaries containing words or phrases associated with predetermined policy positions (Laver 2001). However, as Laver, Benoit, and Garry $(2003,312)$ note, this method does not actually cut down on the human effort as it requires teams of researchers to input large, hand-coded dictionaries, and therefore the likelihood of human error remains.
}

expert surveys. Laver, Benoit, and Garry's computer program Wordscores then counts the number of times each word occurs in the reference texts and compares these counts to word counts from the texts being analyzed. The manifestos are placed on a continuum between the reference texts depending on how similar the word counts are to each reference text. This method clearly constitutes a breakthrough for quantitative content analysis of manifestos. It is easy to implement, and researchers can apply it in almost any setting.

Nevertheless, there are several issues with the Wordscores technique, which our approach aims to address. First, the usefulness of the Wordscores approach hinges on the ability of the researcher to identify appropriate reference texts and reference values. Scholars or experts can reasonably disagree about the extremes of the political space. The choice of reference values becomes even more critical when positions are estimated for more than one dimension. To estimate multiple dimensions, Laver and his co-authors propose that researchers use different reference values on the exact same references texts. This is problematic for two reasons. First, they suggest that it is feasible to generate specific policy dimension estimates from the entire manifesto, even though only some parts of the text deal with the issue under investigation. Second, if analysts have the same two extreme reference texts for all policy dimensions, then party placements hinge on the reference values attributed to the center parties alone. Exogenous measures of a single reference party position could therefore determine the Wordscores results. ${ }^{5}$

Second, Wordscores assigns all words the same weight in the estimation process. Thus, words that occur frequently in all texts and provide little political information, such as conjunctions and articles, pull the document scores towards the center of the space, making these scores incomparable with the original reference values assigned to the reference texts. To make these scores comparable, Laver, Benoit, and Garry (2003) rescale the raw scores by stretching the variance of document scores to equal the variance of the reference text scores. Martin and Vanberg (2008) point out, however, that the particular rescaling algorithm used by Laver, Benoit, and Garry (2003) does not place the transformed scores on the same metric as the reference texts. They offer a new rescaling technique which

\footnotetext{
${ }^{5}$ This is the case for the U.K. example in their article (Laver, Benoit, and Garry 2003). If the researcher fails to use the Liberal Democratic party's manifesto as a reference text, only unidimensional estimation is possible. It is possible to get around this issue by using only sections of the manifesto which deal with the policy dimensions of interest. Proksch and Slapin (2006) parse the reference texts into economic and social sections and then estimate positions using the respective sections only.
} 
leads to different results from those produced by the original rescaling procedure. We avoid this problem entirely by estimating the importance of words for discriminating between party positions rather than treating all words equally.

Finally, time-series estimation is problematic using Wordscores. The Wordscores authors argue that their technique should not be used for time-series analysis because the political lexicon is constantly in flux (Benoit and Laver 2006a, 133). Nevertheless, scholars seem willing to assume that political language is sufficiently stable to use this technique for time-series estimation (Budge and Pennings 2006; Hug and Schulz 2007; McGuire and Vanberg 2005). The bigger issue for time-series estimation using Wordscores is the proper identification of reference texts. This challenge has led researchers to adopt various approaches in order to apply Wordscores to time-series data, all of which come with their own problems. Some analysts concatenate all manifestos over the entire time period in order to produce long reference texts (Budge and Pennings 2006), others run the algorithm twice using two different sets of reference texts from different time periods (Hug and Schulz 2007), and, lastly, some pick two reference texts from different time periods assuming that these constitute the extremes during the entire period (McGuire and Vanberg 2005). ${ }^{6}$ Time-series party positions can be estimated with Wordscores if one is ready to make three assumptions. First, the political lexicon remains sufficiently stable over time, second, chosen reference texts include all relevant words over time, and third, the reference texts represent the most extreme positions during the time period. We propose an approach which does not rely on reference texts and therefore does not make the latter two assumptions.

\footnotetext{
${ }^{6}$ Budge and Pennings (2006) apply Wordscores for a 20-year period by concatenating reference manifestos over this period and assigning averaged left-right scores from the CMP dataset as reference values. As Benoit and Laver point out, "such a procedure is guaranteed to produce flat times series, with the only difference between party estimates being associated with the average positions over the time period-not individual changes at different time periods" (Benoit and Laver 2006a, 134). Hug and Schulz (2007) address the time problem by estimating two different sets of Swiss party positions, using reference values from surveys in 1991 and 2003. The first reference values and texts are used to estimate positions between 1947 and 1995, the second for positions between 1995 and 2003. This creates two problems. First, the vocabulary in the 1991 reference texts might miss important words relevant in the previous elections (1947-91). Second, the authors present the two different sets of estimates as a single time series by concatenating the estimates, even though different texts were used to anchor the parties. Finally, McGuire and Vanberg (2005), estimating the positions of U.S. Supreme Court decisions on religion, chose a conservative decision from 1962 and a liberal decision from 2000 as reference texts, simply asserting that these cases mark the extremes over time.
}

\section{A Scaling Approach to Party Positions}

This article presents an easy-to-implement statistical scaling model to estimate time-series policy positions from political texts. Like other manifesto-based position estimates, this approach assumes that relative word usage of parties provides information about their placement in a policy space. The advantage of this new approach is threefold: its ability to produce time-series estimates, the fact that it does not require the use of reference texts because it instead assumes an underlying statistical distribution of word counts, and, lastly, the ability to use all words in every document and to estimate the importance of each of these words.

This approach draws on a long tradition of quantitative analysis of text. Authorship studies, for example, try to identify authors based on their literary styles. To do so, linguists attempt to uncover characteristics of a particular author by measuring and counting stylistic traits (Holmes 1985; Peng and Hengartner 2002). This technique has been prominently applied in political science to identify authorship of the unsigned Federalist Papers (Mosteller and Wallace 1964).

The process by which words are generated in a text is highly complex, but to facilitate analysis, linguists commonly use a naïve Bayes assumption in applied work (Eyheramendy, Lewis, and Madigan 2003; Lewis 1998). A text is represented as a vector of word counts or occurrences. Individual words are assumed to be distributed at random. Put differently, the probability that each word occurs in a text is independent of the position of other words in the text. It has been pointed out that "while this assumption is clearly false in most real-world tasks, naïve Bayes often performs classification very well" (McCallum and Nigam 1998, 1). Scholars then have tried to determine statistical distributions which most accurately approximate word usage. Commonly used distributions include the Poisson (Mosteller and Wallace 1964), the negative binomial (Mosteller and Wallace 1964) and other Poisson mixtures (Church and Gale 1995), as well as zero-inflated (binomial) distributions (Jansche 2003). All of these distributions are heavily skewed, as is the case of word usage.

Political scientists have started to make use of the naïve Bayes assumption and word frequency distributions to analyze political text. Monroe and Maeda (2004) use a Poisson word count distribution to extract multidimensional positions of U.S. legislators from their speeches. They find that the principal dimension of speech in the U.S. Congress is of a linguistic nature, with the second dimension yielding policy-relevant results.

We analyze word frequencies of party manifestos and assume the frequencies are generated by a Poisson process. 
This particular distribution is chosen because of its estimation simplicity: it only has one parameter, $\lambda$, which is both the mean and the variance. This assumption means that the number of times party $i$ mentions word $j$ in election year $t$ is drawn from a Poisson distribution. This model specification is essentially a Poisson naïve Bayes model and has also been used by Monroe and Maeda (2004). We later apply other distributions to test the robustness of our findings to the distributional assumption. The functional form of the model is as follows:

$$
\begin{gathered}
y_{i j t} \sim \text { Poisson }\left(\lambda_{i j t}\right) \\
\lambda_{i j t}=\exp \left(\alpha_{i t}+\psi_{j}+\beta_{j} * \omega_{i t}\right)
\end{gathered}
$$

where $y_{i j t}$ is the count of word $j$ in party $i$ 's manifesto at time $t, \alpha$ is a set of party-election year fixed effects, $\psi$ is a set of word fixed effects, $\beta$ is an estimate of a word specific weight capturing the importance of word $j$ in discriminating between party positions, and $\omega$ is the estimate of party $i$ 's position in election year $t$ (therefore it is indexing one specific manifesto). We include word fixed effects to capture the fact that some words are used much more often than other words by all parties. The party-election year effects control for the possibility that some parties in some years may have written a much longer manifesto. The parameters of interest are the $\omega$ 's, the position of the parties in each election year, and the $\beta$ 's because they allow us to analyze which words differentiate between party positions.

This model treats each election manifesto as a separate party position and all positions are estimated simultaneously. In other words, the position of party i's manifesto in election $t-1$ does not constrain the position of party i's manifesto in election $t$. If a party maintains a similar position from one election to the next, it means the party has used words in similar relative frequencies over time. On the other hand, if the model indicates that a party moves away from its former position and closer to the position of a rival, it implies that the party's new word choice more closely resembles that of the rival's than of its former self. An alternate specification might assume that a party's position at time $t$ is both a function of its word choice at time $t$ and its position in previous elections. Such a specification might ensure smooth party movement over time, but the movement would both be a function of the word usage and the assumptions about the model's functional form. The current specification has the advantage that observed party movement is, in fact, due to changes in word frequencies and is not an artifact of the model.

As specified, the model estimates positions on a single dimension. Using the entire manifesto text as data, we expect this dimension to correspond to a left-right politics dimension, which we confirm by comparing the results to other estimates of left-right positions. This expectation is justified if manifestos (or other documents being analyzed) are encyclopedic statements of the parties' positions. ${ }^{7}$ To obtain specific policy positions, we modify the text data to be analyzed. For example, we estimate economic positions by running the model on manifesto sections regarding economic policy only. This approach is in contrast to Monroe and Maeda (2004) and other factor analytic techniques, which interpret multidimensional scores ex post. It is also different from Laver, Benoit, and Garry (2003), who estimate different dimensions not by altering the text inputs but by changing the reference values assigned to reference texts.

\section{Estimation}

Unlike a standard Poisson regression model, the entire right-hand side of the equation needs to be estimated. To do this, we use an expectation maximization (EM) algorithm. The EM algorithm is an iterative procedure to compute maximum likelihood estimates for latent variables (McLachlan and Krishnan 1997). The E step involves calculating the expectation of the latent variable as if it were observed. The M step then maximizes the log-likelihood conditional on the expectation. The implementation of this algorithm entails several steps:

\section{Step 1: Calculate starting values.}

We obtain starting values for word fixed effects $(\psi)$ by calculating the logged mean count of each word. For the party fixed effects $(\alpha)$, we use the logged ratio of the mean word count of each party-election manifesto relative to the first party election in our dataset. We set the starting values relative to the first party-election because this party fixed effect is set to zero during the estimation in order to identify the model. To obtain starting values for word weights $(\beta)$ and party positions $(\omega)$ from the word frequencies, we first subtract the starting values for the word and party fixed effects from the logged word frequencies. We then use the left- and right-singular vectors from a singular value decomposition of this matrix as starting values for $\omega$ and $\beta$.

\section{Step 2: Estimate party parameters.}

We estimate party parameters ( $\omega$ and $\alpha$ ) conditional on our expectation for the word parameters. In the first iteration, our expectation of those word parameters equals their starting

\footnotetext{
${ }^{7}$ We thank an anonymous reviewer for pointing this out to us.
} 
values calculated in step 1 . We maximize the following log-likelihood for each party-election $i t$ :

$$
\sum_{j=1}^{m}\left(-\lambda_{i j t}+\ln \left(\lambda_{i j t}\right) * y_{i j t}\right),
$$

where

$$
\lambda_{i j t}=\exp \left(\alpha_{i t}+\psi_{j}^{\text {start }}+\beta_{j}^{\text {start }} * \omega_{i t}\right) .
$$

We use $\omega_{i t}^{\text {start }}$ and $\alpha_{i t}^{\text {start }}$ as starting values in the maximization stage. To identify the model, in addition to setting $\alpha_{1}$ to 0 , we set the mean of all party positions across all elections to 0 and the standard deviation to 1 . This identification strategy allows party positions to change over time relative to the mean position because we fix the total variance of all positions over time. We do not hold the variance or the mean in each election constant, as this would not allow us to make interpretations about party movements over time.

\section{Step 3: Estimate word parameters.}

We estimate word parameters ( $\psi$ and $\beta$ ) conditional on our expectation for the party parameters, which we obtain in step 2. For each word $j$, we maximize the log-likelihood: ${ }^{8}$

$$
\sum_{i t=1}^{n}\left(-\lambda_{i j t}+\ln \left(\lambda_{i j t}\right) * y_{i j t}\right)
$$

where

$$
\lambda_{i j t}=\exp \left(\alpha_{i t}^{\text {step } 2}+\psi_{j}+\beta_{j} * \omega_{i t}^{\text {step2 }}\right) .
$$

Step 4: Calculate log-likelihood.

The log-likelihood of our model is the sum of the individual word log-likelihoods from step 3, which are themselves calculated conditional upon the party $\log$-likelihoods from step 2 :

$$
\sum_{j}^{m} \sum_{i t=1}^{n}\left(-\lambda_{i j t}+\ln \left(\lambda_{i j t}\right) * y_{i j t}\right)
$$

\section{Step 5: Repeat steps $2-4$ until convergence.}

Using the new expectations for the word parameters, we reestimate party parameters (step 2). Then, using those expectations, we reestimate word parameters (step 3). This process is repeated until an acceptable level of convergence, measured as the difference in the log-likelihood from

\footnotetext{
${ }^{8}$ We include in this log-likelihood a relatively diffuse word-specific prior in order to prevent words from carrying infinite weight. The prior belief is that $\beta$ s are distributed normally with mean of zero and standard deviation $\sigma$. This reduces the weight given to words that are mentioned very infrequently (e.g., by only one party in one election) which might otherwise discriminate perfectly. The prior solves a technical problem, but has no effect on our estimated party positions.
}

step 4 between the current and the previous iteration, is reached.

\section{5\% Confidence Intervals}

We obtain confidence intervals for the estimates using a parametric bootstrap. We first estimate all parameters by running the EM algorithm described above. From these ML estimates, we calculate $\lambda_{i j t}$ for each cell in the dataset. We then generate 500 new datasets, each time taking random draws from a Poisson distribution with parameter $\lambda_{i j t}$ for each cell in the word count matrix. Finally, using the ML estimates as starting values, we rerun the algorithm on each of these datasets and estimate 500 new party positions. We use the 0.025 and the 0.975 quantiles of the simulated party positions as an approximate $95 \%$ confidence interval. ${ }^{9}$ Our method for estimating party positions is one of few which allows researchers to measure the uncertainty associated with the estimation. ${ }^{10}$

The parametric bootstrap has the desirable property that the confidence intervals shrink as the number of words increases, something which should be true of confidence intervals of estimates from text analysis (Benoit, Laver, and Mikhaylov 2007; Laver, Benoit, and Garry 2003). We have tested this with a Monte Carlo simulation (Appendix B). First, true parameter values for the party positions were fixed, and the remaining parameter values were drawn from random distributions. Second, simulated word frequencies were generated by taking random draws from a Poisson distribution using the true parameter values to calculate $\lambda_{i j t}$. Finally, the simulation generated confidence intervals from 100 bootstraps. We repeated this procedure, each time increasing the number of unique words being used in the estimation, starting with 25 words and ending with 10,000 words. Because we only increase the number of unique words in this procedure while holding party positions fixed, only the error surrounding these estimates should vary. The simulation demonstrates that the average confidence

${ }^{9}$ The same is possible for the word weights.

${ }^{10} \mathrm{We}$ are not alone in relying on the parametric bootstrap to produce standard errors for this type of analysis. Lewis and Poole (2004) suggest a parametric bootstrap to generate confidence intervals for ideal point estimates obtained from NOMINATE. As far as textbased approaches are concerned, Wordscores generates standard errors through the dispersion of individual word scores around the text's mean score, but these error estimates need to be transformed and rescaled in the same manner as the raw text score (Laver, Benoit, and Garry 2003, 317). Monroe and Maeda (2004) use Gibbs sampling embodied in Bayesian approaches to generate confidence intervals. A recent paper by Benoit, Laver, and Mikhaylov (2007) bootstraps quasi-sentences to generate error estimates for the CMP data. The different approaches to generate standard errors make their comparability across methods difficult. 
interval for party positions decreases substantially as texts get longer. The average 95\% confidence interval is almost six times larger for 25 unique words than for 500 unique words, and the interval is still 2.5 times larger for 500 words compared with 5,000 unique words. The reason for this decrease is that the model treats each unique word as an independent observation. More words mean more data for estimating party positions, and hence smaller confidence intervals.

We have tested several alternatives to this method for producing confidence intervals, but believe the parametric bootstrap provides a good compromise between all of these approaches. The first alternative to our method would involve a nonparametric bootstrap. This approach would sample words from each text with replacement to generate new manifestos. In simulations, we have found this problematic for text data. The simulated manifesto data do not correspond on average to actual manifesto word counts. Infrequent words in the manifesto rarely appear in the simulated data, leading to confidence intervals that do not encompass the ML position estimate. As a second alternative, after obtaining the ML estimates, one could numerically calculate a Hessian matrix, take the negative inverse of this matrix to obtain a variance/covariance matrix for the entire parameter space, and take draws from a multivariate normal distribution to obtain simulated parameter values. However, given the number of parameters typically being estimated in our model, computational obstacles make it impossible to calculate such a large variance/covariance matrix. Third, rather than using a Poisson model, one could revert to a negative binomial model with an overdispersion parameter. Because we use a parametric bootstrap, the confidence intervals we generate are sensitive to our distributional assumptions. Wrong distributional assumptions will generate poor simulated data and lead to invalid estimates of uncertainty. King notes, for example, that the Poisson model will produce biased standard errors in the presence of over- or underdispersion (King 1998, 128). Simulations reveal, however, that confidence intervals produced using the negative binomial model only increase slightly compared with the Poisson model, while the computational effort to generate them vastly increases. This leaves us with the Poisson model using a parametric bootstrap as the most feasible method to obtain confidence intervals.

\section{Implementation in R: WORDFISH}

To implement the routine, we have written a computer program Wordfish for the $R$ statistical language. ${ }^{11}$ As

${ }^{11}$ Wordfish is available at www.wordfish.org. input, the program requires a word frequencies matrix. ${ }^{12}$ The code then takes the word frequency dataset, generates starting values, and runs the algorithm. It outputs the party positions along with the word weights and party and word fixed-effects. In addition, the program can generate confidence intervals from a parametric bootstrap. ${ }^{13}$

Like all statistical models, Wordfish makes several assumptions which researchers should keep in mind when using the method. To estimate positions over time, the model assumes-like users of Wordscores do-that word meanings remain stable. An alternative estimation strategy would hold only a subset of word weights fixed, while allowing the remaining words to have different weights in different time periods. Such an approach would naturally come at the cost of making the model more time consuming to estimate. In addition, it would require subjective judgments on the part of the researcher as to which word parameters to allow to vary and which ones to hold fixed. Researchers would have to state a priori which words' meanings have changed over time and which have not. Because of the inherent difficulty of this task, we opt to assume that all word parameters are fixed over time. Moreover, it is not possible to allow all word parameters to vary across time because the model would be unidentified. To identify the model, we would have to hold party positions fixed, and, given we are interested in party movement over time, this would make little sense. However, we do believe that our approach has an advantage in estimating time-series positions because it uses words from all documents. If the political lexicon changes through words entering and exiting the political dialogue, rather than through words changing meaning, our method does take these changes into account when estimating positions.

With regard to dimensionality, Wordfish assumes the principle dimension extracted from texts captures the political content of those texts. In other words, if researchers want estimates of party positions regarding foreign policy, they should run the program on documents containing information about foreign policy only. Such a decision is

\footnotetext{
${ }^{12}$ Easy-to-use programs are Yoshikoder and jfreq, the latter of which can be called from within $R$ (Lowe 2007), available at http://people. iq.harvard.edu/ wlowe/Software.html.

${ }^{13}$ To demonstrate that our program produces valid parameter estimates, we run a simulation generating word counts using our Poisson model as the data-generating process. First, we set the true parameter values. With the exception of party positions, which we fix, these are drawn at random from a distribution so that the resulting word counts resemble real manifesto data. Second, we generate the word frequencies by taking random draws from a Poisson distribution using the true parameter values to calculate $\lambda_{i j t}$. Finally, we run the code which calculates the starting values and then performs the EM algorithm. The estimated parameters correlate highly with the true values. The correlation between estimated party positions and the truth is always greater than 0.99 . The other parameter estimates correlate with the truth at .9 or greater.
} 
nontrivial. It means that a researcher must carefully read the manifesto to be able to divide it into issue areas, or policy dimensions. Naturally, this requires the knowledge of the document language. Different researchers may make different decisions about which parts of the manifesto refer to economic policy. This leads to an additional source of error which we do not take into account here. If the researcher is not concerned about specific dimensions and is confident the texts under investigation represent the totality of the authors' policy positions, he or she can confidently extract a left-right dimension.

Therefore, when analyzing more than one dimension, we recommend that researchers first define the dimensions ex ante and, second, use only documents that contain information relevant to that dimension. Defining the dimension includes being transparent about what information is being used. For example, a researcher might define a foreign policy dimension as including texts on security, defense, and the United Nations. Others might disagree with this definition and develop a different one. However, only documents which deal with the dimension and issue of interest should be compared. In practice, parties divide manifestos into issue areas themselves to make them more readable and accessible to party members and the electorate. This facilitates the task of defining policy dimensions. In addition, Wordfish gives researchers the ability to analyze the degree to which the estimates capture the dimension under investigation by estimating the word-discrimination parameters. For example, words related to foreign policy should presumably receive a great deal of weight when examining foreign policy texts. If they do not, the researcher may want to consider reexamining the source documents.

\section{Estimates for German Parties, 1990-2005}

We apply this new technique to estimate the positions of German parties in the postreunification era (19902005). ${ }^{14}$ The estimation requires three steps: defining policy dimensions, generating the word frequency dataset, and running the algorithm. We perform two analyses: a

\footnotetext{
${ }^{14}$ German Manifestos in electronic format were made available from the Zentralarchiv für Empirische Sozialforschung, Universität zu Köln. The manifestos were transferred into electronic format by Paul Pennings and Hans Keman, Vrije Universiteit Amsterdam, Comparative Electronic Manifestos Project, in cooperation with the Social Science Reserach Centre Berlin (Andrea Volkens, Hans-Dieter Klingemann), the Zentralarchiv für empirische Sozialforschung, GESIS, Universität zu Köln, and the Manifesto Research Group (chairman: Ian Budge).
}

left-right dimensional analysis using the entire manifesto of each party in each election, and a multidimensional analysis using particular sections of each manifesto (economic, societal, and foreign policies).

Our first analysis uses the entire manifesto text, and we expect our results to capture a basic left-right dimension of German politics. In the second analysis, we calculate positions for individual dimensions of interest. Here, we concentrate our analysis on economic, societal, and foreign policies. ${ }^{15}$ Each manifesto text is thus divided into three separate files. We then run our algorithm on each dimension separately and retrieve three positions for each party. $^{16}$

We follow a scheme applied to German manifestos by König, Blume, and Luig (2003) to divide up the manifestos into policy-specific sections. ${ }^{17}$ The economic dimension captures socioeconomic policies including taxes, revenues, and spending. The foreign dimension covers international political and economic affairs as well as relations with the European Union. Finally, the societal dimension includes diverse areas such as law and order, gender equality, higher education, immigration, housing, and sport. Once the dimensions are defined and the manifesto texts are compiled, we generate a word frequency dataset. The rows of this matrix correspond to a party manifesto from a particular election and the columns to all unique words mentioned in the texts. This means that we have 25 rows (five parties, five elections) and several thousand columns depending on the number of unique

\footnotetext{
${ }^{15}$ We use the term "societal" rather than "social" because we believe the term "societal" is broader. We include several issues in this dimension, such as environmental politics, which are not usually categorized as social politics, but they clearly have societal ramifications.

${ }^{16}$ These are three separate unidimensional positions. In the present context of our model, it is not possible to determine whether these dimensions are orthogonal to one another, nor do we know the relative weights of the dimensions.

${ }^{17}$ The scheme divides up the manifesto as follows. Economic Policy: agriculture, budget, revenue, taxes, consumer protection, deregulation, energy, future policies, general health policy, industrial policy, infrastructure, labor market, pensions, policies concerning Eastern Germany, research and development, trade, welfare state. Societal Policy: animal rights, culture, direct democracy and constitutional reform, anti-drug and HIV policies, children, education (including higher education), environmentalism (except energy policy), family, fight against extremism and terrorism (except on the international level), gender equality, housing, immigration, law and order, traditional morals, multiculturalism, seniors (except pensions), sport. Foreign Policy: defense and security, European Union, global affairs, international terrorism, world trade. Left-Right: economic sections + societal sections + foreign sections. We excluded the following manifesto sections from the analysis: general introduction of a manifesto/preamble, review of the previous parliamentary term, reference to other parties and their manifesto, conclusion of a manifesto.
} 
words for each dimension. While it is possible to estimate positions using the entire party-word matrix, we remove words that parties use infrequently and thus contain little information about their placement. We include a word in the estimation if it was mentioned at least once on average by each party during the period between 1990 and 2005. This has three practical advantages. First, it speeds up the estimation process by eliminating the "long tail" in our dataset. Second, it ensures that our estimation results do not hinge on these infrequently mentioned words. Lastly, it eliminates the possibility that spelling mistakes or other minor and infrequent errors affect our estimates. $^{18}$

\section{Position Estimates}

Figure 1a plots the party position estimates $(\omega)$ for the main left-right dimension. ${ }^{19}$ The estimates reflect several important changes in the party system over time. Since reunification, the former East German communist Party of Democratic Socialism (PDS) has occupied the left end of the political spectrum. The Greens start out on the left in 1990, but move slightly towards the political center up until the most recent election in 2005. This movement reflects the transformation of the Greens from an environmentalist fringe party in the 1980 s to a mainstream governing party by 1998 . Most importantly, our estimates pick up the significant right shift of the Social Democratic Party (SPD) throughout the 1990s. This matches conventional wisdom that Chancellor Gerhard Schröder moved the traditional left-wing socialist party to the political center to recapture government in same way that Tony Blair moved the British Labour Party to the center with his "Third Way." In addition, we see a left shift by both the SPD and the PDS in 2005. This may be explained by a split in the SPD. The left wing of the SPD, led by former party

\footnotetext{
${ }^{18}$ We have run the analysis using all words, and the result correlates very highly with the results we report $(r=.98)$; however, the estimation does take substantially longer.

${ }^{19}$ Appendix A lists the estimated German party positions since 1990 on all dimensions with their respective confidence intervals. It also presents a summary of the estimation results, including the number of unique words, the number of party elections, the number of iterations, the log-likelihood, and the mean absolute difference in the estimated party positions between the last and the previous iteration. To give a rough indication of estimation time, it takes about 45 minutes for the code to converge estimating the main left-right positions ( 25 documents containing approximately 9,000 unique words). Estimation times will increase with both the number and length of texts and also depend upon computing speed. This analysis was performed on a PC with a $1.73 \mathrm{Ghz}$ Intel processor and $760 \mathrm{MB}$ RAM. The bootstrap procedure generating the $95 \%$ confidence intervals can take up to a few days, depending on the number of bootstraps specified.
}

leader Oskar Lafontaine, was upset by the party's rightward movement under Schröder and split off to form a new party together with the PDS, Die Linke. The SPD needed to move left to placate their base and to avoid losing even more party members to Die Linke. Finally, the liberal Free Democrats (FDP) and the conservative Christian Democrats (CDU-CSU) are further to the right and remain relatively stable over time. The FDP tends to be slightly to the right of the CDU-CSU up until 2005, when it moves to the center. The confidence intervals, reported in the appendix, reveal that we can distinguish between parties in all elections except between the Greens and PDS in 1990 and between the CDU-CSU and FDP in 2005. We also find a statistically significant time trend for all parties. Nevertheless, there are several instances in which we cannot statistically distinguish between a party's position and its position in the previous election.

Figures $1 \mathrm{~b}$ through $1 \mathrm{~d}$ plot our party estimates for the economic, societal, and foreign dimensions. On the economic dimension, our analysis confirms that the liberal FDP is clearly the most conservative party, demanding lower taxes and less public spending. This is reflected by the large gap between this party and the CDU-CSU. The two largest German parties (SPD and CDU-CSU) are closest to each other in 2002 and 2005. Following the 2005 election, the two parties formed a grand coalition government. In general, all party positions remain relatively stable over time on this dimension.

The societal dimension captures a wide range of policies, including immigration, education, and environment. The most significant finding for this dimension is that all parties except the Greens move to the left in 2005. In the context of German electoral politics, this was the year when the SPD chancellor decided to hold early elections because some of his own party members had switched over to the PDS. The FDP is still to the right of all parties. This party is often thought to be located between the SPD and the CDU-CSU on social policies. However, the dimension includes more than just social policies, making it difficult to compare this dimension to other estimates of social policy positions.

On foreign policy, a similar ranking of the parties emerges. The Greens, which emerged from an antiwar, pro-environmental social movement, and the PDS are located closely to each other during the first half of the 1990s. Once the Greens enter government in 1998, their policy positions shifts slightly towards the center. The SPD makes its most significant ideological shift throughout the 1990s, when it moves from a leftist position towards a centrist position on foreign policy. Again, this change is likely to be associated with the SPD taking over government responsibility in 1998. The CDU-CSU and the FDP 


\section{(A) Left-Right}

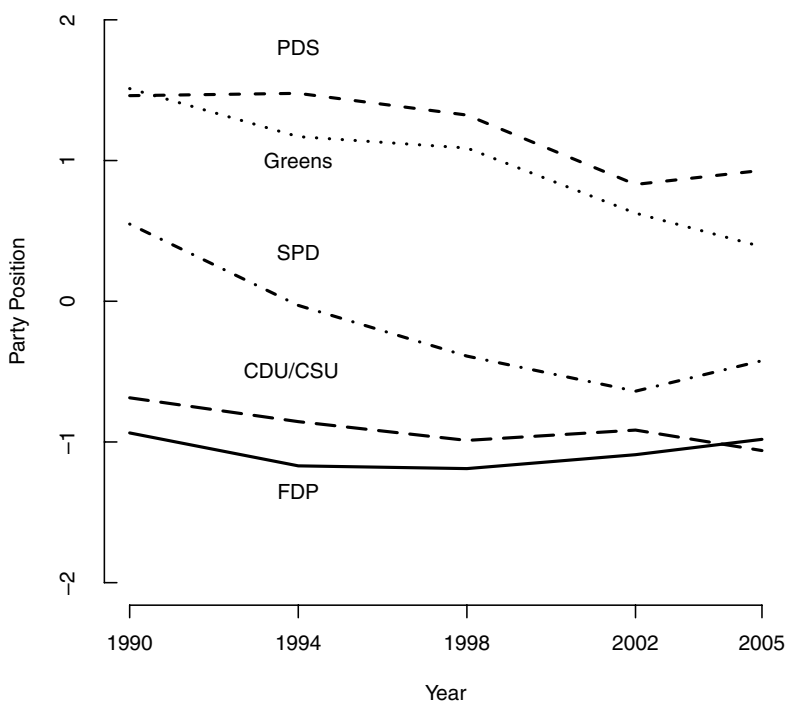

(C) Societal Policy

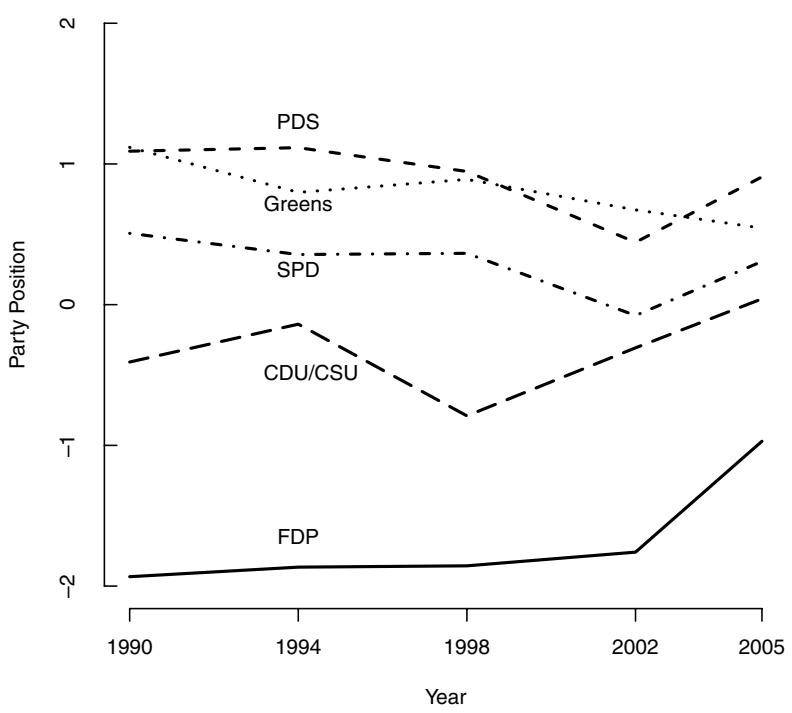

(B) Economic Policy

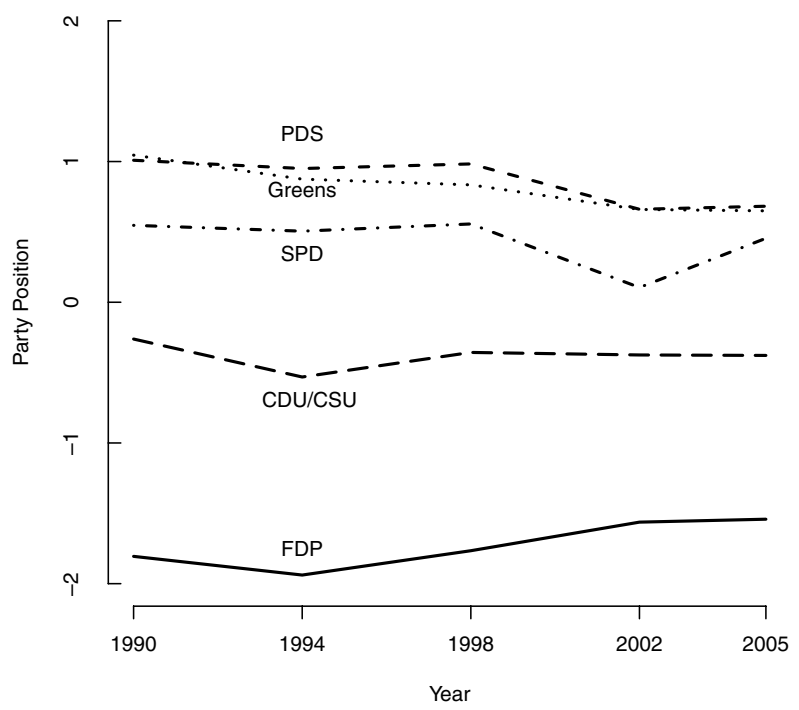

(D) Foreign Policy

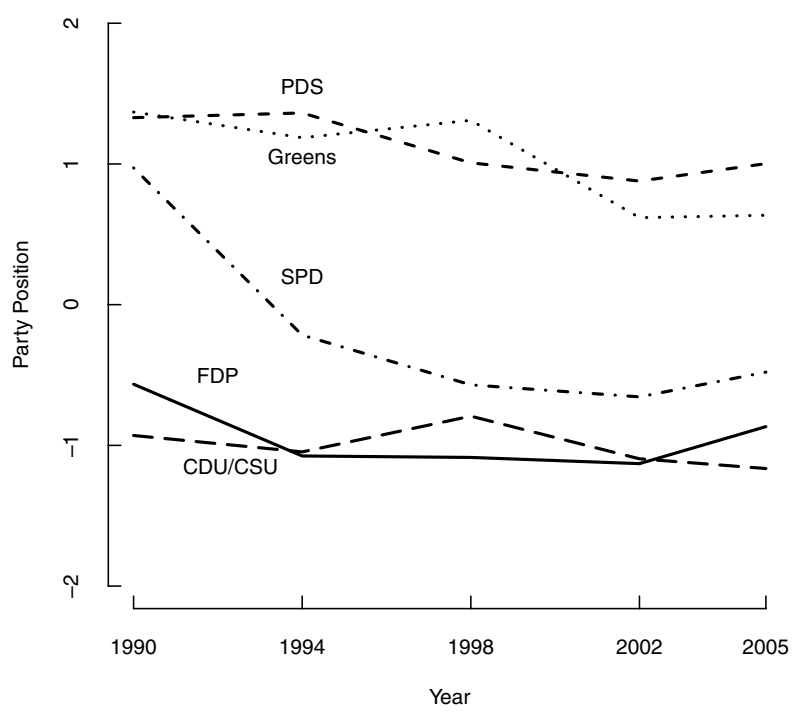

have similar positions. In 1990 and 2005, the FDP is more centrist and located between the two major parties.

A comparison of the size of the confidence intervals reveals that positions estimated from fewer words have larger intervals. For example, the average confidence interval for the economic policy dimension (4,714 words) is $54 \%$ larger than the average confidence interval for the left-right dimension ( 8,995 words). These results confirm the Monte Carlo simulation that more words reduce the uncertainty surrounding the estimates.

\section{Word Analysis: The Political Lexicon}

To further confirm our findings, we check the validity of our results both internally and externally. For internal validiation, we examine the word parameters. We expect to find a particular pattern in the results. Frequent words (e.g., conjunctions, articles, prepositions, etc.) should not discriminate between party manifestos because they do not contain any political meaning. Therefore, they should have large fixed effects associated with weights close to 


\section{FIGURE 2 Word Weights vs. Word Fixed Effects. Left-Right Dimension, Germany 1990-2005 (Translations given in text)}

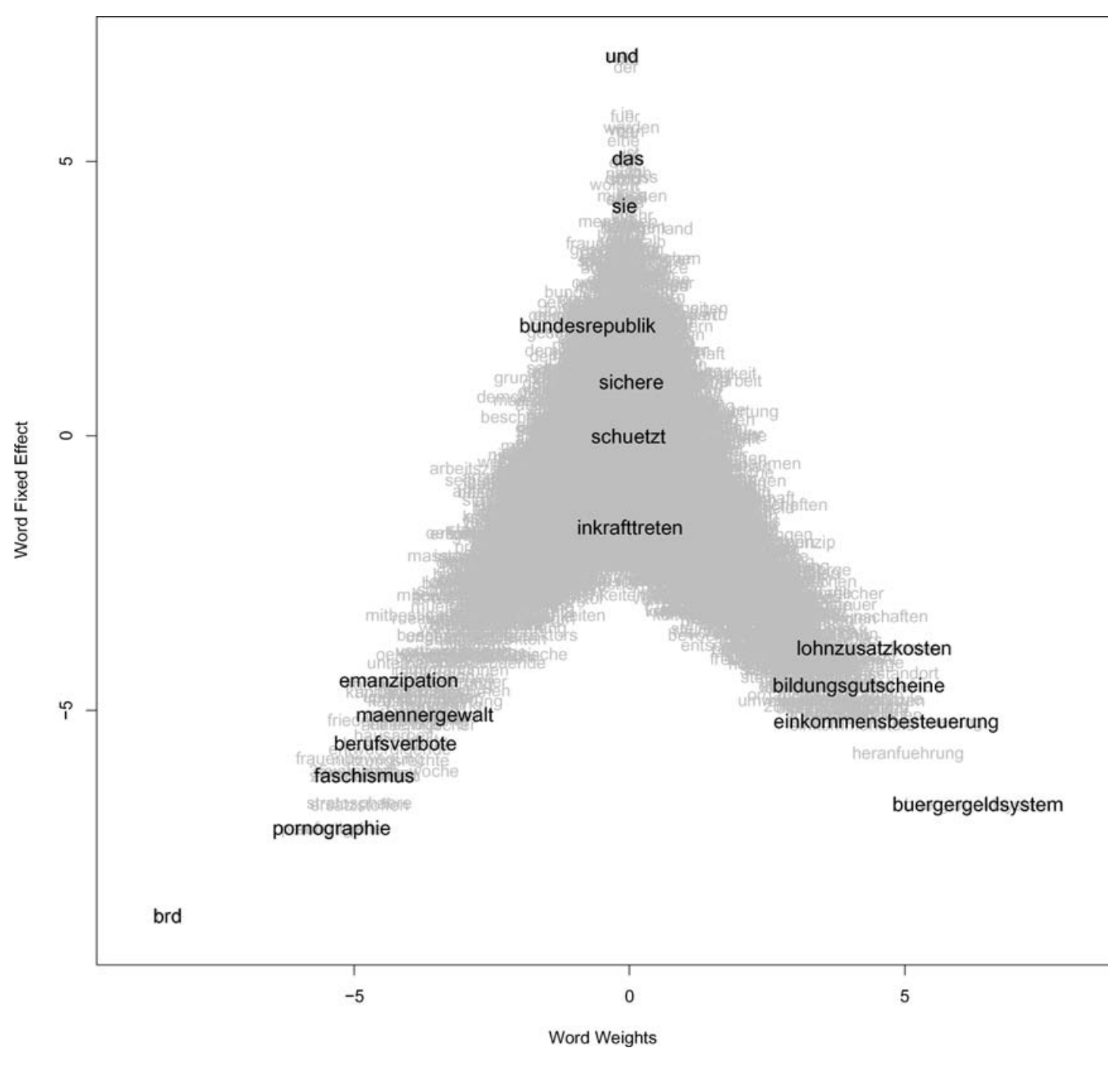

zero. In contrast, as words are mentioned more infrequently, they are more likely to be part of politically relevant language and discriminate between the parties. These words should therefore have smaller fixed effects associated with either positive or negative weights, depending on whether the words place parties on the left or on the right.

Figure 2 plots the estimated word fixed effects against the word weights. The scatterplot confirms our expectations and takes the shape of an "Eiffel Tower of words." Words with a high fixed effect have zero weight, but words with low fixed effects have either negative or positive weight. The graph also highlights some words as examples. Most importantly, words with large weights have a politically relevant connotation. Manifestos on the left mention words like "fascism," "professional ban," "male violence," "emancipation," and "pornography" more often than the ones placed on the right. The largest weight on the left is for the word "BRD," the abbreviation for Federal Republic of Germany, a word that is used primarily by one party, the PDS. While this may appear rather trivial, in the German political context of reunification it is, in fact, an interesting result. It is well known that the official doctrine of the former communist party of East Germany (SED), the predecessor to the PDS, was to refer to West Germany in its abbreviated form in order to demonstrate its rejection of West Germany's claim for sole right of representation. However, the official position of West German governments was to use the full constitutional name (Stevenson 2002, 50). This pattern seems to continue after reunification. On the right, parties use words such as "income taxation," "nonwage labor costs," 
and "education vouchers" more often. The highest weight on this side is for the word "general welfare payments," related to a long-standing proposal by the liberal democratic FDP to bundle up all welfare payments and pay them out to eligible citizens in one lump-sum payment.

Finally, words with large fixed effects do not have discriminating value. The plotted words "entry into force," "protects," "safe," "they/she," "the," and finally the word "and" with the largest fixed effect do not contain much politically relevant information. Their associated weight is close to zero.

Table 1 completes the word analysis for all dimensions and reports the top 10 words placing parties on the left and the right. For instance, in addition to the words shown already in the figure, parties on the left use "womens' movement" and "stratosphere" much more often, whereas parties on the right talk more about "business location" and "mobility."

On the economic dimension, words such as "workers' participation," "quota," "mobility," and "negotiated wages" matter most. All of these are words associated with economic and labor policy. Likewise, on the societal dimension we find references to "process of reunification," "university graduates," "sexuality," and "climate catastrophe." With words as diverse as these, the results reinforce our belief that this is a category capturing societal politics broadly defined. Lastly, words such as "unilateral," "NGOs," "weapons production," and "armies" all clearly refer to the foreign and defense policy domain. In addition, right parties often refer to the European defense and security policy (EDSP), the European police agency (Europol) and to the EU budget. In sum, the fact that the weights are largest for words carrying political meaning demonstrates that our model is capturing the policy space.

\section{Cross-Validation}

Next, we cross-validate our results with existing methods (hand coding of manifestos, expert surveys, and Wordscores). First, we compare our results with the Comparative Manifestos Project left-right scale and three policy scales for Germany, 1990-98 (Budge et al. 2001). The CMP data constitute the only comparable time-series dataset. The three policy scales are market economy (MARKECO), welfare state (WELFARE), and international peace (INTPEACE). We assume that these correspond to our economic, societal, and foreign dimensions. Second, we use expert survey estimates from Benoit and Laver (2006b) on a left-right dimension and on a taxes versus spending dimension for 2002-2003. Finally, we compare our estimates to Wordscores estimates on an economic and social dimension from Laver, Benoit, and Garry (2003) for 1990 and 1994 and from Proksch and Slapin (2006) for 2005.

Table 2 presents the correlations between our and other position estimates. The correlations between our Poisson scaling model and the other three methods is high, suggesting that the techniques provide similar placement of parties in the political space. Unlike what Monroe and Maeda (2004) find in U.S. Congressional speeches, this indicates that the dimension we estimate is political and not solely linguistic. Almost all coefficients range between 0.8 and .98. Only our broad societal category corresponds less well to social and welfare categories of the other measures.

As an additional cross-validation, Figure 3 directly compares our left-right dimension with the Comparative Manifestos Project left-right scale for the years 1990-98. The CMP data suggest major changes in the party system that are inconsistent with standard accounts of German politics. First, it locates the conservative CDU-CSU closer to the Greens than to any other party in 1990, including its governing partner the FDP. Second, it suggests that the social-democratic SPD shoots from being next to the former communists to the position of the free-market Free Democrats, crossing the position of the Green party. It is inconceivable that a major centrist party in an established multiparty system would make such a jump. Moreover, expert survey data do not find that the SPD is to the left of the Greens in 1990 (Huber and Inglehart 1995). In contrast, our method provides less extreme party movements in the 1990s, eliminating the unlikely crossovers suggested by the CMP data. We find that the SPD makes a more modest move relative to the other parties, remaining in the center of the space throughout the period. Our estimates furthermore match the rankings of the parties from the Huber and Inglehart expert survey data. In general, our findings for the German party system correspond well with other methods for estimating party positions. When used as time-series data, our estimates substantially improve upon previous estimates by providing smoother party movements than those found in the CMP data.

\section{Robustness Checks}

While the analysis of the word weights, together with the method's high correlation to other estimates of party positions, indicate that we are capturing a primary leftright dimension in German politics, questions may remain about how robust this technique is to the texts we chose and the model specification we use. Here we demonstrate that our technique is robust to the selection of texts and our assumption about the underlying statistical distribution of word counts. 
Table 1 Top 10 Words Placing Parties on the Left and Right

Top 10 Words Placing Parties on the. . .

\begin{tabular}{|c|c|c|}
\hline Dimension & Left & Right \\
\hline Left-Right & $\begin{array}{l}\text { Federal Republic of Germany (BRD) } \\
\text { immediate (sofortiger) } \\
\text { pornography (Pornographie) } \\
\text { sexuality (Sexualität) } \\
\text { substitute materials (Ersatzstoffen) } \\
\text { stratosphere (Stratosphäre) } \\
\text { women's movement (Frauenbewegung) } \\
\text { fascism (Faschismus) } \\
\text { Two thirds world (Zweidrittelwelt) } \\
\text { established (etablierten) }\end{array}$ & $\begin{array}{l}\text { general welfare payments (Bürgergeldsystem) } \\
\text { introduction (Heranführung) } \\
\text { income taxation (Einkommensbesteuerung) } \\
\text { non-wage labor costs (Lohnzusatzkosten) } \\
\text { business location (Wirtschaftsstandort) } \\
\text { university of applied sciences (Fachhochschule) } \\
\text { education vouchers (Bildungsgutscheine) } \\
\text { mobility (Beweglichkeit) } \\
\text { peace tasks (Friedensaufgaben) } \\
\text { protection (Protektion) }\end{array}$ \\
\hline Economic & $\begin{array}{l}\text { Federal Republic of Germany (BRD) } \\
\text { democratization (Demokratisierung) } \\
\text { to prohibit (verbieten) } \\
\text { destruction (Zerstörung) } \\
\text { mothers (Mütter) } \\
\text { debasing (entwürdigende) } \\
\text { weeks (Wochen) } \\
\text { quota (Quotierung) } \\
\text { unprotected (ungeschützter) } \\
\text { workers' participation (Mitbestimmungs- } \\
\text { möglichkeiten) }\end{array}$ & $\begin{array}{l}\text { to seek (anzustreben) } \\
\text { general welfare payments (Bürgergeldsystem) } \\
\text { inventors (Erfinder) } \\
\text { mobility (Beweglichkeit) } \\
\text { location (Standorts) } \\
\text { negotiated wages (Tarif-Löhne) } \\
\text { child-raising allowance (Erziehungsgeld) } \\
\text { utilization (Verwertung) } \\
\text { savings (Ersparnis) } \\
\text { reliable (verlässlich) }\end{array}$ \\
\hline Societal & $\begin{array}{l}\text { Federal Republic of Germany (BRD) } \\
\text { climate catastrophe (Klimakatastrophe) } \\
\text { sexuality (Sexualität) } \\
\text { pornography (Pornographie) } \\
\text { fascism (Faschismus) } \\
\text { irreplaceable (ersatzlos) } \\
\text { process of reunification (Wende) } \\
\text { women's movement (Frauenbewegung) } \\
\text { substitute materials (Ersatzstoffen) } \\
\text { nuclear facilities (Atomanlagen) }\end{array}$ & $\begin{array}{l}\text { data processing (Datenverarbeitung) } \\
\text { contraception counseling (Verhütungsberatung) } \\
\text { requested (aufgefordert) } \\
\text { questions regarding property (Eigentumsfragen) } \\
\text { competitive sports (Leistungssport) } \\
\text { leisure activities (Freizeitverhalten) } \\
\text { in general (generell) } \\
\text { animal protection law (Tierschutzgesetzes) } \\
\text { social housing fee (Fehlbelegungsabgabe) } \\
\text { university graduates (Hochschulabsolventen) }\end{array}$ \\
\hline Foreign & $\begin{array}{l}\text { Federal Republic of Germany (BRD) } \\
\text { immediately (sofort) } \\
\text { departure (Aufbruch) } \\
\text { foreign political (aussenpolitischer) } \\
\text { unilateral (einseitiger) } \\
\text { Two thirds world (Zweidrittelwelt) } \\
\text { emancipation (Emanzipation) } \\
\text { NGOs (NGOs) } \\
\text { armies (Armeen) } \\
\text { weapons production (Rüstungs- } \\
\text { produktion) }\end{array}$ & $\begin{array}{l}\text { cultural policy (Kulturpolitik) } \\
\text { foreign (auswaertige) } \\
\text { Europol (Europol) } \\
\text { legal protection (Rechtsschutz) } \\
\text { delimitation of competences (Kompetenz- } \\
\text { abgrenzung) } \\
\text { neglected (vernachlässigt) } \\
\text { EDSP (EVSP) } \\
\text { euro-atlantic (euro-atlantischen) } \\
\text { introduction (Heranführung) } \\
\text { EU budget (EU-Haushalt) }\end{array}$ \\
\hline
\end{tabular}




\section{TABle 2 Cross-Validation: Correlations between German Party Position} Estimates

\begin{tabular}{|c|c|c|c|c|}
\hline & \multicolumn{4}{|c|}{ Poisson Scaling Model } \\
\hline & Left-Right & Economic & Societal & Foreign \\
\hline \multicolumn{5}{|l|}{ Hand-coding manifestos } \\
\hline CMP: Left-Right $(\mathrm{n}=15,1990-1998)$ & -0.82 & & & \\
\hline CMP: Markeco $(\mathrm{n}=15,1990-1998)$ & & 0.81 & & \\
\hline CMP: Welfare $(\mathrm{n}=15,1990-1998)$ & & & 0.58 & \\
\hline CMP: Intpeace $(\mathrm{n}=15,1990-1998)$ & & & & 0.81 \\
\hline \multicolumn{5}{|l|}{ Expert Survey } \\
\hline Benoit/Laver 2006: Left-Right $(n=5,2002)$ & -0.91 & & & \\
\hline Benoit/Laver 2006: Taxes-Spending $(\mathrm{n}=5,2002)$ & & 0.86 & & \\
\hline \multicolumn{5}{|l|}{ Wordscores } \\
\hline Laver et al. 2003: Economic $(n=10,1990-1994)$ & & 0.93 & & \\
\hline Laver et al. 2003: Social $(\mathrm{n}=10,1990-1994)$ & & & -0.47 & \\
\hline Proksch/Slapin 2006: Economic $(n=5,2005)$ & & 0.98 & & \\
\hline Proksch/Slapin 2006: Social $(n=5,2005)$ & & & -0.47 & \\
\hline
\end{tabular}

\section{FIGURE 3 Comparison of Left-Right Positions in Germany, 1990-98}

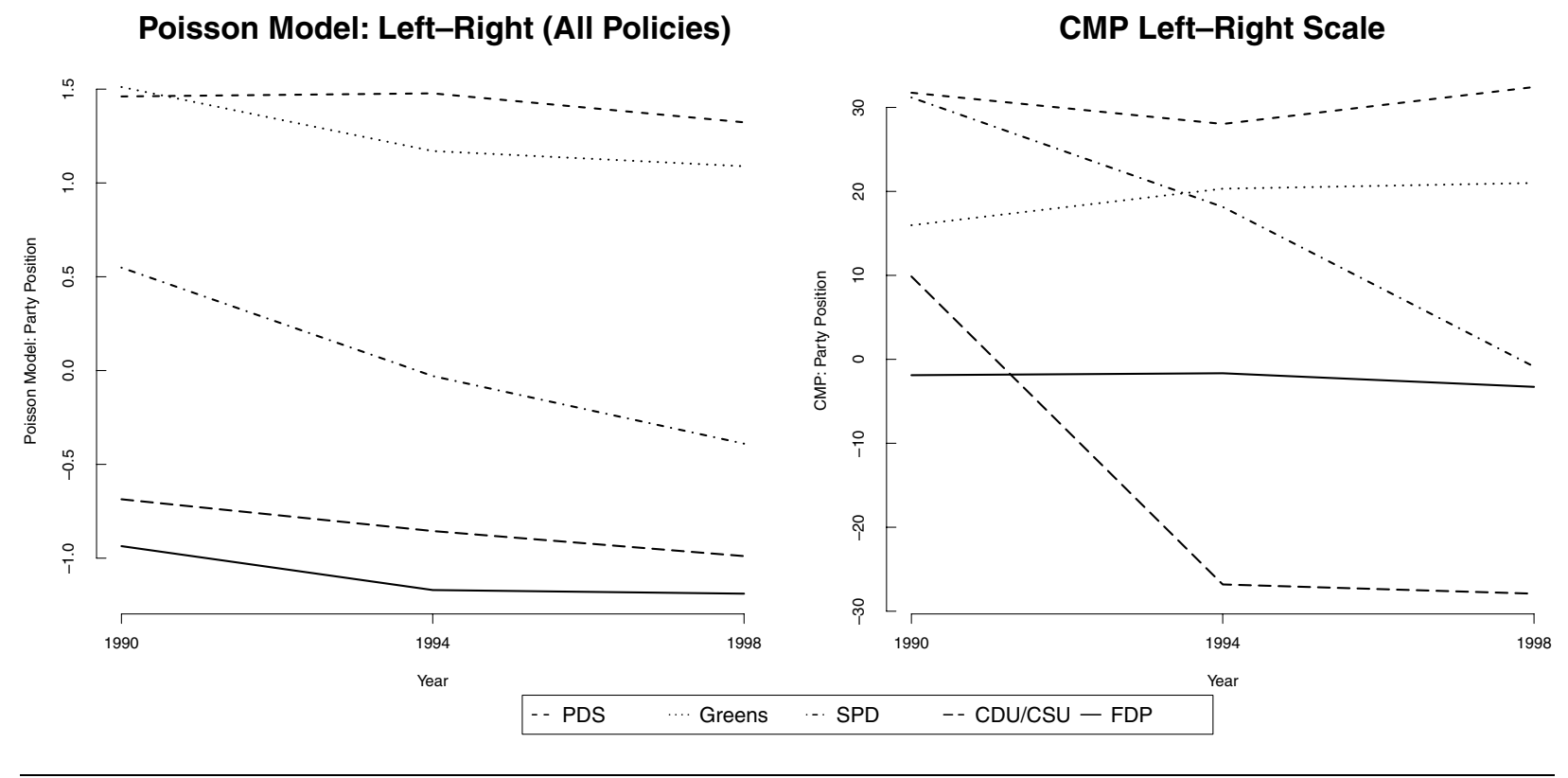

The model specification means that adding or subtracting elections or parties may affect the positions of all remaining parties. To test the extent to which our results hinge on the elections and parties we include in the analysis, we rerun the results dropping single manifestos (one party in one election year), an entire party, and an entire election year. In all cases we get results which correlate very highly with our original estimates of party positions. Our lowest correlation with the original party positions estimates occurs when we drop an entire party, the FDP. When we do this, our results correlate with the remaining original estimates at 0.94 . When we drop the entire election year 2005, the remaining party positions correlate with the original positions at 0.99 . Likewise, we correlate very highly $(r=0.99)$ with our original results when we drop individual manifestos (the CDU-CSU's 1990 manifesto 
and the FDP's 2005 manifesto). This would suggest that even if researchers are unable to obtain all party manifestos, they can still use our method and have a high degree of confidence in their results.

In addition, we examine how well our results hold when we alter our assumption about the underlying statistical distribution of word counts. Although, from the standpoint of estimation, the Poisson distribution has the nice feature that its mean equals its variance, this assumption is unlikely to hold for word-count data (Jansche 2003; Mosteller and Wallace 1964). Therefore, we also estimate our model using a negative binomial distribution with a separate overdispersion parameter for each manifesto. ${ }^{20}$ The additional parameters vastly increase the computation time, in particular when running the parametric bootstrap. The results again correlate very highly with our original party position estimates using the Poisson distribution $(r=0.97)$. The only major difference between the negative binomial estimation and the Poisson estimation is that using the negative binomial estimation we find that the liberal FDP is located just to the left of the CDU, in between the CDU and the SPD, while the FDP was the most right-wing party all years except 2005 using the Poisson distribution.

Finally, we estimate our results using the simplest distribution possible, a log-normal distribution. Here, we simply regress party and word parameters on logged word counts. This also gives us virtually identical results, correlating with our Poisson estimates at 0.94 . Moreover, using the log-normal, we get the same party ordering that we had in the Poisson model. In both the log-normal and negative binomial models, all the party trends remain the same, with SPD and the Greens moving to the center of the political space as they enter government.

\section{Conclusion}

Comparative politics research requires accurate timeseries estimates of party positions. Surprisingly, there is currently no easy-to-implement method that provides valid time-series positions along with measures of their uncertainty. We have presented a methodology which aims to fill this gap. We assume an underlying word frequency distribution in political text and use an EM algorithm to estimate party parameters (positions and fixed

\footnotetext{
${ }^{20}$ We use the NB2 parameterization of the negative binomal found in Cameron and Trivedi (1998). We again include our diffuse normal prior over the estimation of our word weights. An alternative implementation would be to estimate a word-specific overdispersion parameter.
}

effects) as well as word parameters (weights and fixed effects). Our approach adds to existing methods by providing a computer-based text analysis program, Wordfish, which does not require the use of reference texts. Like the Comparative Manifestos Project, our method can create rich time-series data, but does not require teams of potentially error-prone hand coders to do so. At the same time, like Wordscores, we provide easy-to-implement computer code which researchers can apply to virtually any set of political texts. Our method only requires party manifestos of those parties whose positions are to be estimated.

We have demonstrated that our approach produces estimates of party positions which correspond well with positions from other estimation techniques. We are able to accurately portray the German party system in the 19902005 postreunification era. Our estimated positions correlate highly with other methods. However, our approach is much less cost and time intensive, it is easily replicable, and it produces a more accurate time series with uncertainty estimates. In addition, the results for word parameters suggest that the technique captures a political, rather than linguistic, dimension.

Nevertheless, when deciding how to estimate party positions, researchers should carefully assess our set of assumptions compared with those of other computer content analysis programs. First, our method does require analysts to assume word meanings do not vary over time; however, if words enter and exit the political lexicon our approach will still capture their relative importance. Other computer content analysis methods, such as the Bayesian approach taken by Monroe and Maeda (2004), make the same assumptions about word meanings as we do, but are significantly more complicated to implement. Wordscores requires the additional assumptions that all words of interest are contained in the reference texts specified, and these texts represent the extremes over time. Second, researchers must decide whether they prefer to set dimensions ex ante or interpret them ex post. If researchers prefer the latter, only the Bayesian approach of Monroe and Maeda (2004) is currently able to extract more than one dimension from texts. Wordscores requires researchers to identify new reference values and then to assume that both their reference texts and documents of interest contain sufficient information about their dimension of interest to produce meaningful results. We suggest analysts use only documents specifically pertaining to their dimension of interest. This requires that analysts carefully select the texts they are using as data and be familiar with their content. However, we hope that all researchers using computer content analysis do this regardless of the methodology they employ. Lastly, researchers may want to consider speed and ease of use when selecting a methodology. 
When estimating positions at a single point in time for which it is fairly easy to assess the political extremes and identify appropriate reference texts, Wordscores provides the fastest and easiest method for obtaining valid and replicable positions. In situations such as estimating a time series, for which identifying appropriate references texts is difficult or perhaps impossible, our technique provides researchers a straightforward and relatively fast technique for avoiding many of the assumptions necessary when using Wordscores. Finally, researchers may prefer our technique even when estimating positions at a single point in time because we are able to estimate the importance of words for discriminating between texts, thus avoiding the rescaling problem inherent in Wordscores.

There are certain limitations associated with our current model specification and the algorithm which open up a research agenda and which should be addressed in future work. First, although our results appear relatively robust to dropping texts (e.g., removing a party, an election, and an individual manifesto), our algorithm is sensitive to the overall number of texts used. Because each word parameter is estimated using all manifestos, the data must include a sufficient number of manifestos to avoid a small-N problem in the estimates. Second, we have shown that our results seem robust to different distributional assumptions. Nevertheless, future work should examine in more detail the consequences of choosing one distribution over another, paying specific attention to the consequences for uncertainty estimates. Third, our current model assumes that the political lexicon remains similar over time. This is because word parameters are estimated in a time-insensitive manner in order to identify the statistical model allowing all party positions to move. Future versions of the model could relax this assumption for longer time periods and allow weights for a subset of words to vary over time, although researchers would have to make judgments about which words to allow to vary. Finally, we have opted to extract a single dimension over time and our results suggest that it is policy relevant. It would also be possible to rewrite the model to extract more than one dimension. However, we believe that in comparative politics research scholars may prefer policy dimensions whose meaning is set ex ante rather than interpreted ex post.

This set of questions opens up exciting new avenues for research on party positions and ideology estimated from political texts, which is reflected by an increasing number of studies that combine quantitative linguistic analysis with the study of political ideology. Our method takes this approach to examine party ideology over time. The results provide new insights into the German postreunification party system and its political lexicon.

\section{Appendix A}

\section{TABLE A1 Party-Position Estimates (95\% confidence intervals in parentheses)}

\begin{tabular}{llcccc}
\hline Election & Party & Left-Right & Economic & Societal & Foreign \\
\hline \multirow{2}{*}{2005} & PDS & $0.93(0.87,1.01)$ & $-0.68(-0.75,-0.59)$ & $0.91(0.81,1.00)$ & $1.00(0.83,1.13)$ \\
& Greens & $0.39(0.36,0.46)$ & $-0.65(-0.70,-0.59)$ & $0.54(0.47,0.60)$ & $0.64(0.53,0.76)$ \\
& SPD & $-0.42(-0.49,-0.35)$ & $-0.45(-0.52,-0.36)$ & $0.31(0.14,0.44)$ & $-0.48(-0.69,-0.26)$ \\
& CDU & $-1.06(-1.12,-1.00)$ & $0.38(0.29,0.53)$ & $0.04(-0.20,0.22)$ & $-1.16(-1.30,-1.02)$ \\
& FDP & $-0.98(-1.02,-0.94)$ & $1.54(1.46,1.61)$ & $-0.97(-1.09,-0.86)$ & $-0.87(-0.95,-0.74)$ \\
& PDS & $0.83(0.78,0.90)$ & $-0.66(-0.73,-0.58)$ & $0.44(0.31,0.54)$ & $0.89(0.79,0.96)$ \\
& Greens & $0.63(0.60,0.70)$ & $-0.66(-0.70,-0.60)$ & $0.67(0.60,0.74)$ & $0.62(0.50,0.74)$ \\
& SPD & $-0.64(-0.69,-0.59)$ & $-0.11(-0.17,0.00)$ & $-0.08(-0.20,0.02)$ & $-0.66(-0.78,-0.53)$ \\
& CDU & $-0.92(-0.96,-0.87)$ & $0.37(0.31,0.50)$ & $-0.31(-0.46,-0.20)$ & $-1.10(-1.20,-0.99)$ \\
& FDP & $-1.09(-1.14,-1.06)$ & $1.56(1.49,1.62)$ & $-1.76(-1.82,-1.67)$ & $-1.13(-1.22,-1.04)$ \\
& PDS & $1.32(1.27,1.35)$ & $-0.98(-1.07,-0.95)$ & $0.95(0.89,1.00)$ & $1.01(0.89,1.09)$ \\
& Greens & $1.09(1.06,1.12)$ & $-0.83(-0.89,-0.80)$ & $0.89(0.84,0.94)$ & $1.31(1.24,1.37)$ \\
& SPD & $-0.39(-0.46,-0.32)$ & $-0.56(-0.61,-0.48)$ & $0.36(0.25,0.47)$ & $-0.57(-0.75,-0.39)$ \\
& CDU & $-0.99(-1.04,-0.94)$ & $0.36(0.27,0.50)$ & $-0.79(-0.97,-0.66)$ & $-0.79(-0.90,-0.68)$ \\
& FDP & $-1.19(-1.24,-1.17)$ & $1.77(1.67,1.81)$ & $-1.86(-1.91,-1.76)$ & $-1.09(-1.18,-1.00)$
\end{tabular}


TABle A1 (Continued)

\begin{tabular}{llcccc}
\hline Election & Party & Left-Right & Economic & Societal & Foreign \\
\hline 1994 & PDS & $1.48(1.42,1.50)$ & $-0.95(-1.05,-0.89)$ & $1.12(1.07,1.19)$ & $1.36(1.21,1.49)$ \\
& Greens & $1.17(1.13,1.20)$ & $-0.87(-0.93,-0.84)$ & $0.80(0.75,0.84)$ & $1.19(1.10,1.25)$ \\
& SPD & $-0.03(-0.08,0.05)$ & $-0.51(-0.56,-0.42)$ & $0.36(0.25,0.45)$ & $-0.22(-0.41,-0.03)$ \\
& CDU & $-0.86(-0.91,-0.80)$ & $0.53(0.44,0.68)$ & $-0.14(-0.29,-0.02)$ & $-1.05(-1.17,-0.92)$ \\
1990 & FDP & $-1.17(-1.21,-1.14)$ & $1.94(1.85,1.95)$ & $-1.87(-1.90,-1.78)$ & $-1.08(-1.15,-1.01)$ \\
& PDS & $1.46(1.40,1.48)$ & $-1.01(-1.11,-0.98)$ & $1.09(1.04,1.16)$ & $1.33(1.20,1.44)$ \\
Greens & $1.51(1.46,1.52)$ & $-1.05(-1.15,-1.03)$ & $1.12(1.10,1.18)$ & $1.37(1.31,1.44)$ \\
& SPD & $0.55(0.47,0.65)$ & $-0.55(-0.63,-0.44)$ & $0.51(0.36,0.64)$ & $0.97(0.79,1.13)$ \\
CDU & $-0.69(-0.78,-0.60)$ & $0.26(0.11,0.50)$ & $-0.41(-0.60,-0.23)$ & $-0.93(-1.10,0.74)$ \\
Unique Words & FDP & $-0.94(-0.98,-0.89)$ & $1.81(1.71,1.84)$ & $-1.93(-1.99,-1.84)$ & $-0.57(-0.67,-0.45)$ \\
Iterations & 8995 & 4714 & 4817 & 2200 \\
Log-Likelihood & 111 & 178 & 26 & 18 \\
Difference in $\omega$ & $8.22 * 10^{-4}$ & $2.48 * 10^{-3}$ & $2.19 * 10^{-3}$ & $2.10 * 10^{-3}$
\end{tabular}

\section{Appendix B}

\section{FIGURE B1 Simulation: Text Length and Uncertainty Estimates}

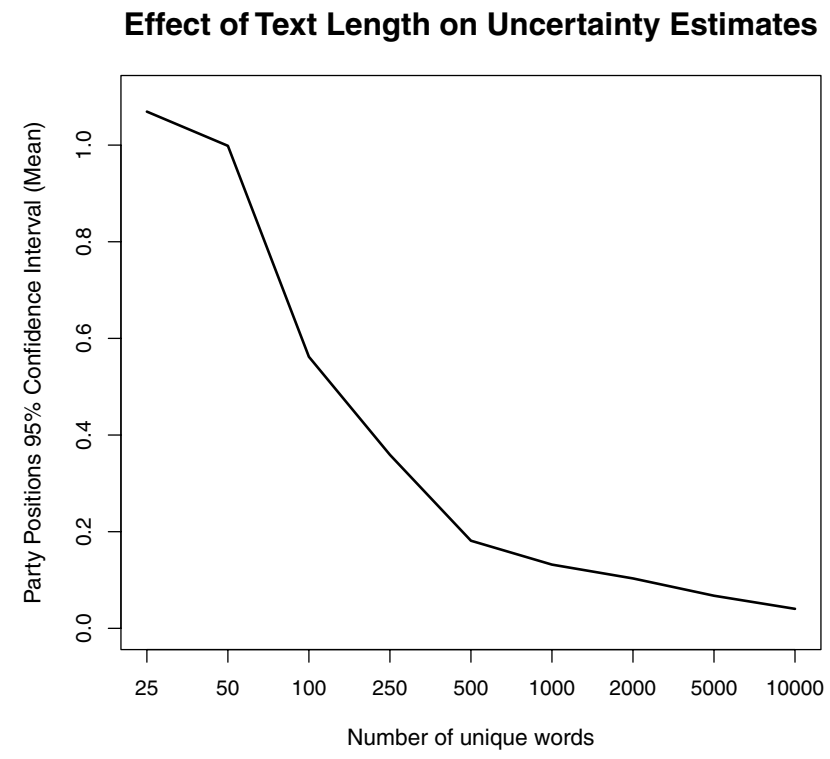

Note: Simulations based on 25 parties and 100 bootstraps. Party positions are identified with mean $=0$ and stand. dev. $=1$.

\section{References}

Baron, David P. 1991. "A Spatial Bargaining Theory of Government Formation in Parliamentary Systems." American Political Science Review 85(1): 137-64.

Bawn, Kathleen. 1999. "Money and Majorities in the Federal Republic of Germany: Evidence for a Veto Players Model of Government Spending." American Journal of Political Science 43(3): 707-36.

Benoit, Kenneth, and Michael Laver. 2006a. "Benchmarks for Text Analysis: A Response to Budge and Pennings." Electoral Studies 26(1): 130-35.

Benoit, Kenneth, and Michael Laver. 2006b. Party Policy in Modern Democracies. London: Routledge.

Benoit, Kenneth, Michael Laver, and Slava Mikhaylov. 2007. "Estimating Party Policy Positions with Uncertainty Based on Manifesto Codings." Prepared for the 2007 annual meeting of the American Political Science Association.

Budge, Ian, Hans-Dieter Klingemann, Andrea Volkens, Judith Bara, and Eric Tanenbaum. 2001. Mapping Policy Preferences: Estimates for Parties, Electors, and Governments 1945-1998. Oxford: Oxford University Press.

Budge, Ian, and Paul Pennings. 2006. "Do They Work? Validating Computerised Word Frequency Estimates Against Policy Series." Electoral Studies 26(1): 121-29.

Budge, Ian, David Robertson, and Derek Hearl. 1987. Ideology, Strategy, and Party Change: Spatial Analyses of Post-War Election Programmes in 19 Democracies. Cambridge: Cambridge University Press.

Cameron, A. Colin, and Pravin K. Trivedi. 1998. Regression Analysis of Count Data. Cambridge University Press. 
Castles, Francis G., and Peter Mair. 1984. "Left-Right Political Scales: Some Expert Judgements." European Journal of Political Research 12(1): 73-88.

Church, Kenneth W., and William A. Gale. 1995. "Poisson Mixtures.” Natural Language Engineering 1(2): 163-90.

Crombez, Christophe. 1996. "Minority Governments, Minimal Winning Coalitions and Surplus Majorities in Parliamentary Systems." European Journal of Political Research 29(1): 129.

de Swaan, Abram. 1973. Coalition Theories and Cabinet Formation. Amsterdam: Elsevier.

Druckman, James N., Lanny W. Martin, and Michael F. Thies. 2005. "Influence without Confidence: Upper Chambers and Government Formation." Legislative Studies Quarterly 30(4): 529-48.

Druckman, James N., and Michael F. Thies. 2002. "The Importance of Concurrence: The Impact of Bicameralism on Government Formation and Duration." American Journal of Political Science 46(4): 760-71.

Eyheramendy, Susana, David Lewis, and David Madigan. 2003. "On the Naive Bayes Model for Text Categorization." Proceedings of the Ninth International Workshop on Artificial Intelligence and Statistics.

Franzese, Robert J. 2002. Macroeconomic Policies of Developed Democracies. Cambridge: Cambridge University Press.

Gabel, Matthew J., and John D. Huber. 2000. "Putting Parties in Their Place: Inferring Left-Right Ideological Positions from Party Manifestos Data." American Journal of Political Science 44(1): 94-103.

Garrett, Geoffrey. 1998. Partisan Politics in the Global Economy. Cambridge: Cambridge University Press.

Hallerberg, Mark, and Scott Basinger. 1998. "Internationalization and Changes in Tax Policy in OECD Countries: The Importance of Domestic Veto Players." Comparative Political Studies 31(3): 321-52.

Holmes, D. I. 1985. "The Analysis of Literary Style-A Review." Journal of the Royal Statistical Society 148(4): 328-41.

Huber, John D., and Ronald Inglehart. 1995. "Expert Interpretations of Party Space and Party Locations in 42 Societies." Party Politics 1(1): 73-111.

Hug, Simon, and Tobias Schulz. 2007. "Left-Right Positions of Political Parties in Switzerland.” Party Politics 13(3): 30530.

Jansche, Martin. 2003. "Parametric Models of Linguistic Count Data." 41st Annual Meeting of the Association for Computational Linguistics, Sapporo, Japan, 288-95.

King, Gary. 1998. Unifying Political Methodology: The Likelihood Theory of Statistical Inference. Ann Arbor: University of Michigan Press.

Klingemann, Hans-Dieter. 1995. "Party Positions and Voter Orientations." In Citizens and the State, ed. Hans-Dieter Klingemann and Dieter Fuchs. Oxford: Oxford University Press, 183-205.

König, Thomas, Till Blume, and Bernd Luig. 2003. "Policy Change without Government Change? German Gridlock After the 2002 Elections." German Politics 12(2): 86-146.

Laver, Michael, ed. 2001. Estimating the Policy Positions of Political Actors. London: Routledge.

Laver, Michael. 2006. "Legislatures and Parliaments in Comparative Context." In Oxford Handbook of Political Economy, ed. Barry Weingast and Donald Wittman. Oxford: Oxford University Press, 121-40.

Laver, Michael, Kenneth Benoit, and John Garry. 2003. "Extracting Policy Positions from Political Texts Using Words as Data." American Political Science Review 97(2): 311-32.

Laver, Michael, and Ian Budge, eds. 1992. Party, Policy, and Government Coalitions. London: St. Martin's Press.

Laver, Michael, and W. Ben Hunt. 1992. Policy and Party Competition. New York: Routledge, Chapman and Hall.

Lewis, David D. 1998. "Naive (Bayes) at Forty: The Independence Assumption in Information Retrieval." Proceedings of the 10th European Conference on Machine Learning, 4-15.

Lewis, Jeffrey B., and Keith T. Poole. 2004. "Measuring Bias and Uncertainty in Ideal Point Estimates via the Parametric Bootstrap." Political Analysis 12(2): 105-27.

Lowe, Will. 2007. "Yoshikoder: Multilingual Content Analysis Software in Java." http://www.yoshikoder.org.

Martin, Lanny W., and Georg Vanberg. 2008. "A Robust Transformation Procedure for Interpreting Political Text.” Political Analysis 16(1): 93-100.

McCallum, Andrew, and Kamal Nigam. 1998. "A Comparison of Event Models for Naive Bayes Text Classification." AAAI98 Workshop on Learning for Text Categorization.

McGuire, Kevin T., and George Vanberg. 2005. "Mapping the Policies of the U.S. Supreme Court: Data, Opinions, and Constitutional Law." Prepared for delivery at the annual meeting of the American Political Science Association, Washington, DC.

McLachlan, Geoffrey J., and Thriyambakam Krishnan. 1997. The EM Algorithm and Extensions. New York: Wiley.

Monroe, Burt L., and Ko Maeda. 2004. “Talk's Cheap: TextBased Estimation of Rhetorical Ideal-Points.” 21st Annual Summer Meeting, Society for Political Methodology, Stanford University.

Mosteller, Frederick, and David L. Wallace. 1964. Applied Bayesian and Classical Inference: The Case of the Federalist Papers. New York: Springer Verlag.

Peng, Roger D., and Nicolas W. Hengartner. 2002. "Quantitative Analysis of Literary Style." The American Statistician 56(3): 175-85.

Poole, Keith, and Howard Rosenthal. 1985. "A Spatial Model for Legislative Roll Call Analysis.” American Journal of Political Science 29(2): 357-84.

Proksch, Sven-Oliver, and Jonathan B. Slapin. 2006. "Institutions and Coalition Formation: The German Election of 2005." West European Politics 29(3): 540-59.

Stevenson, Patrick. 2002. Language and German Disunity: A Sociolinguistic History of East and West in Germany, 1945-2000. Oxford: Oxford University Press.

Strom, Kaare. 1984. "Minority Governments in Parliamentary Democracies." Comparative Political Studies 17(2): 199227.

Tsebelis, George. 2002. Veto Players: How Political Institutions Work. Princeton, NJ: Russell Sage/Princeton University Press.

Wallerstein, Michael. 1999. "Wage-Setting Institutions and Pay Inequality in Advanced Industrialized Societies." American Journal of Political Science 43(3): 649-80.

Warwick, Paul. 1992. "Ideological Diversity and Government Survival in Western European Parliamentary Democracies." Comparative Political Studies 25(3): 332-61. 